\title{
THE ROLE OF MINDFULNESS IN UNETHICAL PURCHASING NEGOTIATION
}

\author{
DOI: 10.17261/Pressacademia.2017.720 \\ RJBM- V.4-ISS.3-2017(19)-p.427-433 \\ Yi-Hui Ho ${ }^{1}$,Chieh-Yu Lin ${ }^{2}$ \\ ${ }^{1}$ Chang Jung Christian University, No.1, Changda Rd., Gueiren District, Tainan City, 71101, Taiwan. vicky@mail.cjcu.edu.tW \\ ${ }^{2}$ Chang Jung Christian University, No.1, Changda Rd., Gueiren District, Tainan City, 71101, Taiwan. jylin@mail.cjcu.edu.tw
}

To cite this document

Ho, Yi-Hui \& Lin, Chieh-Yu. (2017). The role of mindfulness in unethical purchasing negotiation. Research Journal of Business and Management (RJBM), V.4, Iss.3, p.427-433.

Permemant link to this document: http://doi.org/10.17261/Pressacademia.2017.

Copyright: Published by PressAcademia and limited licenced re-use rights only.

\begin{abstract}
Purpose- Negotiation occurs all the time in purchasing practices of businesses, and is inevitable for purchasing professionals when encountering purchasing conflict. Ethical negotiation is considered the vital requirement in maintaining long-term and close buyer-supplier relationships. This study aims to explore the relationship between mindfulness and unethical negotiation.

Methodology- This study will take purchasing professionals in Taiwan as research subjects to investigate the relationship between mindfulness and unethical negotiation.

Findings- Research findings reveal that there is a significant negative relationship between mindfulness and unethical negotiation. Purchasing professionals with different mindfulness are expected to exhibit different purchasing negotiation behaviors.

Conclusion- Mindfulness refers to self-awareness of one's present experience including his/her own thoughts and what is happening in the environment. While the process of negotiation contains a series of judgment and decision-making, mindfulness may possibly influence purchasing professionals' unethical negotiation.
\end{abstract}

Keywords: Mindfulness, unethical negotiation, purchasing professionals, Taiwan.

JEL Codes: M10, M12, M14

\section{INTRODUCTION}

Purchasing professionals play a key role in keeping long-term relationships with suppliers and achieving the company's strategic objectives (Bell, Oppenheimer \& Bastien, 2002). They often extend the boundary between internal functions and external suppliers by coordinating the flow of goods and services in business. Based on Knight, Tu, and Preston's (2014) study, negotiation skills have been ranked the top three skills of purchasing professionals; therefore, negotiation plays an important role in maintaining buyer-supplier relationship (Sharland, 2001). Most purchasing professionals spend a considerable portion of time either negotiating with suppliers for things that are important to their purchasing duty or resolving disputes among others in the workplace.

Negotiation occurs all the time in purchasing practices of businesses, and is inevitable for purchasing professionals when encountering purchasing conflict. It is the process of reviewing, planning, and analyzing used by two or more parties to reach acceptable agreements or compromises. A negotiation situation usually encounters a conflict of interest (Lewicki, 1983). Accordingly, when a purchasing negotiation conflict happens, tension may occur between purchasing professionals' duty to both the employer and supplier. Each purchasing professional may possibly perceived questionable negotiation in different ways, and leads to different decision makings and outcomes. Ethical negotiation in purchasing are considered to be one of the essential requirements in maintaining close buyer-supplier relationships (Reitz, Wall \& Love, 1998). Most suppliers no doubt view ethics of their buyers as an important foundation to build relationships characterized by trust (Bell et al., 2002; Robertson \& Rymon, 2001). Therefore, understanding the acceptable and appropriate negotiation tactics of purchasing professionals is helpful for those who want to build close buyer-supplier relationships. An amount of empirical studies have examined ethical issues in purchasing negotiation practices; but, there is still lack of research focusing on analyzing the effect of purchasing professionals' mindfulness on unethical purchasing negotiation.

Mindfulness refers to self-awareness of one's present experience including his/her own thoughts and what is happening in the environment (Brown \& Ryan, 2003). It is "a state of being attentive to and aware of what is taking place in the present" 
(Brown \& Ryan, 2003, p.822), and also the concept of being present with open or receptive awareness and attention, which is likely to assist one's judgment and decision-making. Mindful individuals are more likely to recognize ethical challenges or to appreciate conflicts of interest (Ruedy \& Schweitzer, 2010). As how people perceive is related to what they do, individuals' mindfulness plays an essential role in how their ethics actions are shaped. Purchasing professionals with different mindfulness are expected to exhibit different purchasing negotiation behaviors. While the process of negotiation contains a series of judgment and decision-making (Brach, 2008), mindfulness may possibly influence purchasing professionals' unethical negotiation. Although several studies investigated unethical purchasing negotiation, none of them analyzed the relationship between mindfulness and unethical purchasing negotiation. To fill the research gap, the purpose of this study is to explore the effect of purchasing professionals' mindfulness on unethical purchasing negotiation.

The remainder of the paper proceeds as follows. The next section reviews the literature and proposes research hypothesis. The third section illustrates the research methodology, and the fourth section shows the research findings. The final section concludes with suggestions.

\section{LITERATURE REVIEW}

\subsection{Unethical Purchasing Negotiation}

Negotiation is "a process of potentially opportunistic interaction by which two or more parties, with some apparent conflict, seeks to do better through jointly decided action than they could otherwise" (Lax \& Sebenius, 1986, p. 11). It is a process to reach an agreement and get what you want from others by using back and forth communications when two sides have some shared and opposed interests (Fisher, Ury \& Patton, 1991). Conflicts of interests often occur between two or more individuals or parties, and each side will find ways to solve the conflicts. Most people expect a give and take process that each side will modify their opening position to reach a compromise (Lewicki, Saunders, \& Barry, 2006). Ideally, negotiating parties or individuals interact to each other to attain mutual beneficial agreement; however in many cases, people who encounter challenges to achieve goals for each side may possibly use unethical tactics to their own good. Purchasing professionals, often act as negotiators and coordinators between suppliers and the company, are likely to use questionable negotiation practices to achieve desired outcomes. It is sometimes difficult for purchasing professionals to balance and achieve mutual benefits.

In general, negotiation is usually a mix of competition and cooperation (Ogilvie \& Kidder, 2008; Rubin, 2002) which includes both integrative and distributive features. The interdependence between these two poles creates a dilemma for the negotiator in his decision making process (Rubin, 2002). Dilemmas arise because the tactical requirements of distributive bargaining are opposite to those of integrative bargaining. Managing the dilemmas between these two features presents a central challenge to negotiators. These dilemmas consist in fixing the objectives, deciding on the level of cooperation, honesty and trust but also on the ways and means and toughness (Grzeskowiak \& Al-Khatib, 2009).

Although ethical negotiation exists when negotiators are willing to find a fair solution with honesty by exchanging information in a moral and social acceptable manner without abusing their power, Robinson, Lewicki, \& Donahue (2000) argue that negotiators might attempt to find opportunistic advantages in negotiation. To achieve desired outcomes, several negotiators are likely to use questionable practices during negotiation process (Pruit, 2002). Reitz et al. (1998) concluded ten questionable negotiation tactics, including lies, puffery, deception, weakening the opponent, strengthening one's own position, nondisclosure, information exploitation, change of mind, distraction, and maximization. Lewicki and Robinson (1998) proposed five common unethical negotiation: (1) traditional competitive bargaining; (2) attacking negotiating opponent's network; (3) making false promise to negotiating partner; (4) misrepresentation of information; and (5) inappropriate information gathering about negotiating partner's business position. These five types of unethical negotiation have been widely analyzed in the research of negotiation ethics (e.g., Al-Khatib, Malshe \& Abdulkader, 2008; Banai, Stefanidis, Shetach, \& Özbek, 2014; Ma, 2010; Rivers, 2009; Volkema, 2004; Volkema \& Fleury, 2002; Westbrook, Arendall \& Padelford, 2011).

For example, purchasing professionals may engage in competitive bargaining such as exaggerate their demands, hide their bottom line from the suppliers, or remain tentative about their negotiation timeline. They may even use more questionable tactics such as making false promises and pretending that the company has intention to perform some action without actually having the intention to follow through. Furthermore, purchasing professionals may also misrepresent the information. They may distort their acceptable settlement points so that they can convince the suppliers to provide them with more concessions. Some purchasing professionals may also choose to attack the other company's network by seducing members of the opponent company to join in or provide secret information. They may also involve in inappropriate information gathering tactic such as paying bribes to collect the floor price of the merchandise. Therefore, this study adopts Lewicki and Robinson's (1998) perspective to investigate purchasing professionals' ethically questionable purchasing negotiation. 
Potential predictors of unethical negotiation behavior are usually categorized into individual (or demographic) factors, and cultural factors in numbers of studies (Al-Khatib et al., 2008; Banai et al., 2014; Sobral \& Islam, 2013; Volkema, 2004). In addition to individual and cultural factors, business ethics research has suggested that organizational factors are important predictors of an individual's ethical decision-making (O'Fallon \& Butterfield, 2005; Olekalns, Horan, \& Smith, 2014; Reb, Narayanan, \& Ho, 2013). However, none of these studies focused on the effect of mindfulness on unethical purchasing negotiation. This study therefore attempts to investigate the relationship between mindfulness and unethical purchasing negotiation.

\subsection{Mindfulness}

Mindfulness has been discussed in diverse perspectives though numbers of studies have noted about the complexity of defining mindfulness (e.g., Chiesa, 2013; Langer \& Moldoveanu, 2000; Mikulas, 2011). The concept of mindfulness was derived from the ancient Buddhist tradition which represented a quality of consciousness called "bare attention" (Brown, Ryan, \& Creswell, 2007). From the perspectives of psychology, mindfulness is the process of drawing novel distinctions including open to novelty, being sensitive to content and perspective, creating new categories, changing mindsets, challenging assumptions, breaking set, getting involved, and taking responsibility (Langer, 1989; Langer \& Moldoveanu, 2000). Moreover, mindfulness can be considered the awareness that emerges through paying attention on purpose, in the present moment, and non-judgmentally to the unfolding of experience moment by moment. (Kabat-Zinn, 2003), or can also be regarded as the behavior of the mind which actively maximize the breadth and clarity of awareness (Mikulas, 2011). Based on Brown and Ryan (2003), mindfulness is "a state of being attentive to and aware of what is taking place in the present" (Brown \& Ryan, 2003, p.822). They argue that this "present-centered attention-awareness" concept is fundamental to defining mindfulness (Brown \& Ryne, 2003, p.824).

Regarding the essentials of mindfulness, studies have suggested a variety of elements about mindfulness. For example, Bishop et al. (2004) suggest that mindfulness is considered a particular focus of attention characterized by two distinct features: (1) self-regulation of attention to the immediate present moment, and (2) the adoption of an orientation marked by curiosity, openness, and acceptance. Shapiro et al. (2006) indicate a three-component model of mindfulness including attention, attitude and intention to explain how mindfulness practice affects positive change. Cardaciotto et al. (2008) suggest two key components of mindfulness: present-moment awareness and acceptance. Moreover, Baer, Smith, and Allen (2004) suggest four elements of mindfulness which includes observing, describing, acting with awareness, and accepting without judgment. Baer et al. (2006) and Baer (2007) then propose a five-factor structure of mindfulness characterized by nonreactivity, observing, acting with awareness, describing, and nonjudging. Because of the various definitions of mindfulness, Chiesa (2013) suggests researchers may refer to the specific aspect or process of mindfulness using in their research. Although numbers of above studies have proposed various elements of mindfulness, the "presentcentered attention-awareness" suggested by Brown and Ryan (2003) was often used; accordingly, the study will refer to present-center attention-awareness mindfulness as defined by Brown and Ryan (2003).

Being mindful is often critical not only at work but also in decision-makings. Langer and Moldoveanu (2000) indicate that the consequences of mindfulness include (1) greater sensitivities to the environment, (2) more openness to new information, (3) the creation of new categories for structuring perception, and (4) enhanced awareness of multiple perspectives in problem solving. (Langer \& Moldoveanu, 2000, p.2). Studies also found that participants in mindful conditions were better able to use the objects creativity when the need for a novel use of the object arose (Langer \& Piper, 1987). The increases in mindfulness are positively related to creativity (Langer, Heffernan, \& Kiester, 1988), self-regulated behavior and positive emotional states (Brown \& Ryan, 2003), willingness to tolerate uncomfortable emotions and sensations (Levitt et al., 2004), job performance (Dane \& Brummel, 2014), and culturally sensitive and reflective (Tuleja, 2014). Supervisors' trait mindfulness is also found positively related to employee well-being and performance such as inrole performance and organizational citizenship behaviors (Reb, Narayanan, \& Chaturvedi, 2014). Moreover, individuals in high mindfulness are more likely to behave ethically, value upholding ethical standards, use a principled approach to ethical decision-making, and cheat less (Ruedy \& Schweitzer, 2010). When applying to the workplace, mindfulness is found positively associated with employee well-being performance (Reb et al.,2014) and performance (Dane \& Brummel, 2014).

For example, Ruedy and Schweitzer (2010) studied the effect of mindfulness on ethical decision making, and found individual mindfulness will benefit his/her ethical standard upholding. Reb et al. (2013) found that employee mindfulness is positively related to employee well-being and performance, and therefore suggest the critical role of mindfulness at the workplace. They also found organizational constraint positively related to employee absent-mindedness and negatively related to employee awareness, task routineness was found positively related to employee absent-mindedness, and the supervisor support positively predicted employee awareness. As a result, they propose that employee mindfulness can be enhanced through supervisor support and organizational factors. In addition, Dane and Brummel (2014) found workplace mindfulness is positively related to job performance and negatively related to turnover intention.

Based on above discussions, mindfulness is the concept of being present with open or receptive awareness and attention, 
which is likely to benefit one's judgment and decision-making. As the process of negotiation contains a series of judgment and decision-making, mindfulness may possibly influence purchasing professionals' unethical negotiation.

\subsection{Mindfulness and Unethical Purchasing Negotiation}

Mindfulness promotes self-awareness of one's environment (Rudey \& Schweitzer, 2010); therefore, increasing mindful awareness can deepen and broaden social understanding. Benefits of being mindful to the present may also extend to complex social interactions. Mindful negotiators are likely to be self-aware and often attached to the emotions of others. On the other hand, mindless negotiators may possibly encounter misunderstanding and misperceptions in negotiation occasions. As a consequence, the role of mindfulness is essential that may possibly impact on negotiation success.

Numbers of studies suggest that mindfulness may improve negotiation performance (e.g., Brach, 2008; Kiken \& Shook, 2011; Kopelman, Avi-Yonah, \& Varghese, 2012; Reb \& Narayanan, 2014; Riskin, 2009; Ruedy \& Schweitzer, 2010). For instance, Brach (2008) focuses on interest-based negotiation and proposes that negotiators may enhance negotiator effectiveness by examining four thematic parallels: purpose, presence, acceptance, and connectedness. By incorporating these four facets, negotiators can also make their negotiating experiences more satisfying. Kiken and Shook (2011) suggests mindfulness can increase positive judgment and reduces negativity bias. They also found that people in mindfulness condition reveal higher level of optimism. Kopelman et al. (2012) argue that mindfully handling emotions in negotiation will result in better negotiation performance.

In addition, Riskin (2009) discusses mindful awareness from the viewpoint of law profession. He argues that mindfulness can assist individuals think clearly and to recall ethical values, rules, or standards, and therefore bring about the ethical conduct of lawyers, negotiators, and mediators. Ruedy \& Schweitzer (2010) examine the relationship between mindfulness and ethical decision-making, and found that mindfulness may promote ethical intention. Individuals with higher mindfulness are more likely to reveal higher ethical standards. Reb and Narayanan (2014) conduct four laboratory experiments to examine the effect of mindful attention on distributive negotiation. They found mindful negotiators are more likely to focus their minds on the task instead of getting distracted. Mindful negotiators are also more satisfied with the negotiation outcome and process.

Accordingly, mindfulness may disengage individuals from thoughts, habits or improper behavior, and foster self-endorsed behavioral regulation. It helps recognize the situation and avoid biases in negotiation process so that desired negotiation outcome may be achieved. While mindfulness could encourage a greater awareness of one's environment and self-serving cognitions (Brown \& Ryan,2003) and self-awareness may enhance conscious of ethical considerations (Ruedy \& Schweitzer, 2009), this study proposes the following hypothesis: There is a negative relationship between mindfulness and unethical purchasing negotiation.

\section{METHODOLOGY}

\subsection{Data Collection}

Data were collected through a questionnaire survey of a thousand of purchasing professionals across a broad spectrum of industries in Taiwan. These purchasing professionals were contacted by researchers via e-mail and telephone to solicit their cooperation. A packet containing a cover letter with the promise of protecting the confidentiality of responses, a questionnaire, and a pre-addressed return envelope were mailed to each of the sampled purchasing professionals. After the questionnaires were delivered, a follow-up to the purchasing professionals was conducted by e-mail and telephone to remind them of the importance of their responses and thank them for their assistance. A total of 631 respondents returned the questionnaires. Like any other ethics research, this study has the potential to suffer from responses that state what is socially desirable, not what is practiced. The fact that the survey was conducted voluntarily and anonymously may have minimized this problem to some extent.

\subsection{Measurement}

This study used the Self-reported Inappropriate Negotiation Strategies Scale (SINS Scale) and the Mindful Attention Awareness Scale (MASS) to investigate respectively purchasing professionals' unethical purchasing negotiation and mindfulness. The SINS was originally introduced by Lewicki and his colleagues (Lewicki \& Robinson, 1998; Robinson et al., 2000) to measure an individual's perception of unethical negotiation tactics. The instrument consists of 16 items in five factors representing five unethical tactics in negotiation contexts: (1) traditional competitive bargaining; (2) attacking negotiating opponent's network; (3) making false promises to negotiating partner; (4) misrepresentation of information; and (5) inappropriate information gathering about negotiating partners' business position. Respondents are asked to consider these items in the context of a situation that they are negotiating for something very crucial to their business and themselves. They rate the degree of appropriateness they perceived in each item on a seven-point Likert scale format, with 1 indicates not appropriate at all while 7 indicates very appropriate. Except for four items in the scale for information 
misrepresentation, all other four scales have three items respectively. This instrument has been used and confirmed its validity in a number of studies.

To measure the mindfulness of purchasing professionals, this study used the Mindful Attention Awareness Scale (MAAS) developed by Brown and Ryan (2003). This measurement particularly emphasizes on the perspective of present-centered mindfulness, and is so far the most widely used questionnaire in mindfulness studies (Chiesa, 2013). The MASS was used to measure individual differences in the frequency of mindful states over time (Brown \& Ryan, 2003). This scale has 15-item questionnaire scored on a 6-point Likert scale from 1 (almost always) to 6 (almost never) for participants to rate how often they experience these states.

\section{RESEARCH RESULTS}

The measurement items of determinant factors were submitted to factor analysis. The result of factor analysis confirms the construct validity of this study. According to the reliability coefficients, the smallest value of Cronbach's alpha for this study is 0.7972 , which implies that the sampling results are reliable. Table 1 shows the perceptions of unethical negotiation tactics of respondents.

Table 1: A Summary of Perceptions of Unethical Negotiation Tactics of Respondents

\begin{tabular}{ll}
\hline & Score \\
\hline Inappropriate information gathering & 3.18 \\
Information misrepresentation & 2.36 \\
Competitive bargaining & 4.05 \\
Attacking opponent network & 2.97 \\
Making false promises & 2.69 \\
\hline
\end{tabular}

To explore the relationship between mindfulness and unethical purchasing negotiation, the regression analysis was used in the study. The results reveal that proposed research hypothesis is supported. There is a significant negative relationship between mindfulness and unethical purchasing negotiation ( $\beta=-0.21$ ).

Being mindful is often critical not only at work but also in decision-makings. Mindfulness promotes self-awareness of one's environment; therefore, increasing mindful awareness can deepen and broaden social understanding. Benefits of being mindful to the present may also extend to complex social interactions. Mindfulness can assist individuals think clearly and to recall ethical values, rules, or standards, and therefore bring about the ethical conduct of lawyers, negotiators, and mediators. Mindfulness may promote ethical intention. Individuals with higher mindfulness are more likely to reveal higher ethical standards. Mindful negotiators are more likely to focus their minds on the task instead of getting distracted.

Mindfulness could encourage a greater awareness of one's environment and self-serving cognitions, and self-awareness may enhance conscious of ethical considerations. Mindful negotiators are likely to be self-aware and often attached to the emotions of others. On the other hand, mindless negotiators may possibly encounter misunderstanding and misperceptions in negotiation occasions. As a consequence, the role of mindfulness is essential that may possibly impact on negotiation success. Mindful negotiators are also more satisfied with the negotiation outcome and process. Accordingly, mindfulness may disengage individuals from thoughts, habits or improper behavior, and foster self-endorsed behavioral regulation. It helps recognize the situation and avoid biases in negotiation process so that desired negotiation outcome may be achieved.

\section{CONCLUSION}

This study has explored the relationship between mindfulness and unethical negotiation for purchasing professionals in Taiwan. The research findings revealed that there is a significant negative relationship between mindfulness and unethical purchasing negotiation. This study can provide a thorough analysis of mindfulness and unethical negotiation of purchasing professionals by analyzing the influences of mindfulness on unethical purchasing negotiation. This study is expected to contribute to make up for the lack of research on analyzing mindfulness and unethical negotiation of purchasing professionals, and expand the research scopes of both mindfulness and negotiation ethics.

Furthermore, while most previous studies focused on purchasing ethics in the Western society, the current study can make significant contributions towards the ethics literature by providing valuable empirical insight into mindfulness and unethical negotiation in the context of purchasing in Taiwan - a non-Western environment. The study is expected to have profound implications for Taiwanese businesses as it can provide a basis for understanding their purchasing professionals' 
perceptions of unethical negotiation tactics in purchasing situations. This study might help businesses to establish guidelines to help purchasing professionals to act ethically when facing dilemmas and to prevent them from resorting to unethical negotiation practices.

\section{REFERENCES}

Al-Khatib, F. A., Malshe, A., \& Abdulkader, M. (2008). Perception of unethical negotiation tactics: A comparative study of US and Saudi managers. International Business Review, 17, 78-102.

Baer, R. A. (2007). Mindfulness, assessment and transdiagnostic processes. Psychological Inquiry, 18, $238-242$.

Baer, R. A., Smith, G. T., \& Allen, K. B. (2004). Assessment of mindfulness by self-report: The Kentucky inventory of mindfulness skills. Assessment, 11, 191-206.

Baer, R. A., Smith, G. T., Hopkins, J., Krietemeyer, J., \& Toney, L. (2006). Using self-report assessment method to explore facets of mindfulness. Assessment, 13, 27-45.

Banai, M., Stefanidis, A., Shetach, A., \& Özbek, M. F. (2014). Attitudes towards ethically questionable negotiation tactics: A two-country study. Journal of Business Ethics, 123(4), 669-685.

Bell, G. G., Oppenheimer, R. J., \& Bastien, A. (2002). Trust deterioration in an international buyer-supplier relationship. Journal of Business Ethics, 36(1/2), 65-78.

Bishop, S. R., Lau, M., Shapiro, S., Carlson, L., Anderson, N. D., \& Carmody, J. (2004). Mindfulness: A proposed operational definition. Clinical Psychology, 11, 230-241.

Brach, D. (2008). A logic for the magic of mindful negotiation. Negotiation Journal, 24(1), 25-44.

Brown, K. W. \& Ryan, R. M. (2003). The benefits of being present: Mindfulness and its role in psychological well-being. Journal of Personality and Social Psychology, 84(4), 822-848.

Brown, K. W., Ryan, R. M., \& Creswell, J. D. (2007). Mindfulness: Theoretical foundations and evidence for its salutary effects. Psychological Inquiry, 18(4), 211-237.

Cardaciotto, L., Herbert, J. D., Forman, M. E., Moitra, E., \& Farrow, V. (2008). The assessment of present-moment awareness and acceptance. Assessment, 15, 204-223.

Chiesa, A. (2013). The difficulty of defining mindfulness: Current thought and critical issues. Mindfulness, 4(3), 255-268.

Dane, R., \& Brummel, B. J. (2014). Examining workplace mindfulness and its relations to job performance and turnover intention. Human Relations, 67(1), 105-128.

Fisher, R., Ury, W., \& Patton, B. (1991). Getting to yes: Negotiating agreement without giving in, 2nd Ed. NY: Penguin.

Grzeskowiak, S., \& Al-Khatib, F. A. (2009). Does morality explain opportunism in marketing channel negotiations? The moderating role of trust. International Journal of Retail and Distribution Management, 37(2), 142-160.

Kabat-Zinn, J. (2003). Mindfulness-based interventions in context: Past, present and future. Clinical Psychology: Science and Practice, 10(2), 144-156.

Kiken, L. G., Shook, N. G. (2011). Looking up: Mindfulness increases positive judgments and reduces negativity bias. Social Psychological and Personality Science, 2(4), 425-431.

Knight, L., Tu, Y. H., \& Preston, J. (2014). Integrating skills profiling and purchasing portfolio management: An opportunity for building purchasing capability. International Journal of Production Economics, 147, 271-283

Kopelman, S., Avi-Yonah, O., \& Varghese, A. K. (2012). The mindful negotiator: Strategic emotion management and wellbeing. In K. Cameron \& G. Spreitzer, The Oxford Handbook of Positive Organizational Scholarship. Oxford University Press, Ch. 44, 591-600.

Langer, E. J. (1989). Mindfulness. Reading, MA: Addison-Wesley.

Langer, E. J., \& Moldoveanu, M. (2000). The construct of mindfulness. Journal of Social Issues, 56(1), 1-9.

Langer, E. J., \& Piper, A. (1987). The prevention of mindlessness. Journal of Personality and Social Psychology, 53, $280-287$.

Langer, E. J., Heffernan, D., \& Kiester, M. (1988). Reducing burnout in an institutional setting: An experimental investigation. Unpublished manuscript, Harvard Univesity, Cambridge, MA.

Lax, D. A., \& Sebenius, J. K. (1986). The manager as negotiator. NY: Free Press.

Levitt, J. T., Brown, T. A., Orsillo, S. M., Barlow, D. H. (2004). The effects of acceptance versus suppression of emotion on subjective and psychophysiological response to carbon dioxide challenge in patients with panic disorder. Behavior Therapy, 35(4), 747-766. 
Lewicki, R. J. (1983). Lying and deception: A behavioral model. Negotiating in Organizations. In Lewicki R. J. (eds). Beverly Hills, CA: Sage Publications.

Lewicki, R. J., \& Robinson, R. J. (1998). Ethical and unethical bargaining tactics: An empirical study. Journal of Business Ethics, 17, 665-682.

Lewicki, R.J., Saunders, D. M., \& Barry, B. (2006). Negotiation. $5^{\text {th }}$ Ed., McGraw Hill: NY.

Ma, Z. (2010). The SINS in business negotiations: Explore the cross-cultural differences in business ethics between Canada and China. Journal of Business Ethics, 91, 123-135.

Mikulas, W. L. (2011). Mindfulness: Significant common confusions. Mindfulness, 2(1), 1-7.

O'Fallon, M. J., \& Butterfield, K. D. (2005). A review of the empirical ethical decision-making literature: 1996-2003. Journal of Business Ethics, 59(4), 375-413.

Ogilvie, J. R., \& Kidder, D. L. (2008). What about negotiator styles? International Journal of Conflict Management, 19(2), 132-147.

Olekalns, M., Horan, C. J., \& Smith, P. L. (2014). Maybe it's right, maybe it's wrong: Structural and determinants of deception in negotiation. Journal of Business Ethics, 122(1), 89-102.

Pruit, D. (2002). Strategy in negotiation. In V. A. Kremenyuk (Ed.), International Negotiation: Analysis, Approaches, Issues, pp.85-96. San Francisco, CA: Jossey-Bass.

Reb, J., \& Narayanan, J. (2014). The influence of mindful attention on value claiming in distributive negotiations: Evidence from four laboratory experiments. Mindfulness, 5(6),756-766.

Reb, J., Narayanan, J., \& Chaturvedi, S. (2014). Leading mindfully: Two studies on the influence of supervisor trait mindfulness on employee well-being and performance. Mindfulness, 5(1), 36-45.

Reb, J., Narayanan, J., \& Ho, Z. W. (2013). Mindfulness at work: Antecedents and Consequences of employee awareness and absentmindedness. Mindfulness. DOI: 10.1007/s12671-013-0236-4

Reitz, H. J., Wall, Jr., J. A., \& Love, M. S. (1998). Ethics in negotiation: oil and water or good lubrication? Business Horizons, May/June, 5-14.

Riskin, L. L. (2009). Awareness and ethics in dispute resolution and law: Why mindfulness tend to foster ethical behavior. South Texas Law Review, 50, 493-503.

Rivers, C. (2009). Negotiating with the Chinese: EANTs and all. Thunderbird International Business Review, 51(5), 473-489.

Robertson, D. C., \& Rymon, T. (2001). Purchasing agents' deceptive behavior: a randomized response technique study. Business Ethics Quarterly, 11(3), 455-479.

Robinson, R. J., Lewicki, R. J., \& Donahue, E. M. (2000). Extending and testing a five factor model of ethical and unethical bargaining tactics: introducing the SINS scale. Journal of Organizational Behavior, 21, 649-664.

Rubin, J. Z. (2002). The actors in negotiation. In V. A. Kremenyuk (Ed.), International Negotiation: Analysis, Approaches, Issues, pp.97-109. San Francisco, CA: Jossey-Bass.

Ruedy, N. E., \& Schweitzer, M. E. (2010). In the moment: The effect of mindfulness on ethical decision making. Journal of Business Ethics, 95(1), 73-87.

Shapiro, S. L., Carlson, L. E., Astin, J. A., \& Freedman, B. (2006). Mechanisms of mindfulness. Journal of Clinical Psychology, 62(3), 373-386.

Sharland, A. (2001). The negotiation process as a predictor of relationship outcomes in international buyer-supplier arrangements. Industrial Marketing Management, 30(7), 551-559.

Sobral, F., \& Islam, G. (2013). Ethically questionable negotiation: The interactive effects of trust, competitiveness, and situation favorability on ethical decision making. Journal of Business Ethics, 117(2), 281-296.

Tuleja, E. A. (2014). Developing cultural intelligence for global leadership through mindfulness. Journal of Teaching in International Business, 25(1), 5-24.

Volkema, R. J. (2004). Demographic, cultural, and economic predictors of perceived ethicality of negotiation behavior: A nine-country analysis. Journal of Business Research, 57, 69-78.

Volkema, R. J., \& Fleury, M. T. L. (2002). Alternative negotiating conditions and the choice of negotiation tactics: A cross-cultural comparison. Journal of Business Ethics, 36, 381-398.

Westbrook, K. W., Arendall, C. S., \& Padelford, W. M. (2011). Gender, competitiveness, and unethical negotiation strategies. Gender in Management: An International Journal, 24(4), 289-310. 